2

3

4

5

6

19

20

21

22

23

24

25

26

27

28

29

30

31

32

33

34

\title{
Combined use of nitrogen and coatings to improve the quality of mechanically
} harvested Manzanilla olives

Eva Ramírez, Antonio H. Sánchez, Concepción Romero, Manuel Brenes*

Food Biotechnology Department, Instituto de la Grasa (IG-CSIC), Avda. Padre García Tejero 4, 41012-Seville, Spain

*Corresponding author. Tel.: +34954690850; fax: +34954691262.

E-mail address: brenes@cica.es (M. Brenes).

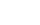

7




\section{ABSTRACT}

37 The combined effect of an edible coating and a nitrogen atmosphere on the quality of 38 Manzanilla olives mechanically harvested and processed as Spanish-style green olives 39 was assessed. The percentage of olives free of any brown spots ranged between 35$4050 \%, 10-25 \%$ and 50-65 \% for fruit directly processed, storage under nitrogen and 41 coated and storage under nitrogen respectively. Moreover, olives stored in the open air 42 developed brown spots due to the oxidation of oleuropein. By contrast, the anoxic 43 conditions prevented oleuropein from undergoing enzymatic oxidation but not from its 44 enzymatic hydrolysis. Hence, the phenolic derivative HyEDA was formed in olives 45 stored under nitrogen, and this substance was rapidly oxidized in the open air to give 46 rise to brown spots although to a lesser extent in the coated fruit. Therefore, the 47 postharvest storage of coated olives under nitrogen can be a good method to prevent 48 bruise damage in mechanically harvested fruit.

51 Keywords: Olive, postharvest, nitrogen, coating, bruising, phenolic, PPO activity 52 


\section{Introduction}

Among table olive varieties (Olea europaea L.), the Manzanilla is one of the most susceptible to bruising during harvesting and postharvest handling (JiménezJiménez, Castro-García, Blanco-Roldán, Ferguson, Rosa \& Gil-Ribes, 2013; Zipori, Dag, Tugendhaft \& Birger, 2014). These olives are traditionally picked by hand which is a very high cost operation and requires many workers. For this reason, mechanical harvesting is highly demanded by farmers (Ferguson, 2006; Saracoglu, Ucer \& Ozarslan, 2011; Gambella, Dimauro \& Paschino, 2013). In Spain, low prone to bruising fruit such as the Hojiblanca variety are mechanically harvested as well as most olives intended for oil extraction. However, fruit damage has limited the use of this technology for the Manzanilla variety, particularly when they must be processed as Spanish-style green olives.

Bruising damage consists of a browning of the olive area mainly affected by the fruit-fruit and fruit-branch impact during mechanical harvesting. The cellular tissue is disrupted, leading to the release of polyphenoloxidase (PPO) and its phenolics substrate, resulting in physical contact. In the presence of oxygen, oleuropein, which is the major phenolic compound in olive pulp, is oxidized, giving rise to the formation of brown polymers (García, Romero, Medina, García, De Castro \& Brenes, 2008; Sánchez, Romero, Ramírez \& Brenes, 2013; Ramírez, García-García, De Castro, Romero \& Brenes, 2013).

Early on, Ben-Shalom, Harel \& Mayer (1978) found that dipping the injured olives in a week $\mathrm{NaOH}$ solution $(0.2-0.4 \%)$ could prevent the formation of the brown spots, and this method has been confirmed later by other researchers (Rejano, Sánchez \& Vega, 2008; Zipori et al., 2014). Nevertheless, the alkaline solution must be refrigerated to prolong the postharvest period by at least 10-12 h. In addition, leaves and small branches must be removed at the groves before the olives are covered with the weak alkaline solution to avoid blockage into the pumps. An alternative method to preserve the olive quality of damaged fruit is based on the use of a nitrogen atmosphere (Segovia-Bravo, García-García, López-López \& Garrido-Fernández, 2012). Bruising was negligible on olives stored under these anoxic conditions for $6 \mathrm{~h}$ but brown spots rapidly appeared after the exposure of the fruit to open air conditions (Sánchez et al., 2013). It seemed that oxygen penetrated into the olive flesh very fast and the oxidative reactions started again once the nitrogen atmosphere was released. Upon the arrival of 
the olives to the factories, at least 15 min are necessary to cover them with the $\mathrm{NaOH}$ solution used for their processing as Spanish-style green olives, and therefore strategies for reducing browning during this period are mandatory.

The effects of edible coatings on retarding browning in harvested fruit have been extensively reported (Hernández-Muñoz, Almenar, Del Valle, Velez \& Gavara, 2008; Chauhan, Raju, Singh \& Bawa, 2011; Pereira, Machado \& Costa, 2013). They provide a semi-permeable barrier to oxygen resulting in browning inhibition that has been suggested for glycerol coated olives (Sánchez et al., 2013). Hence, the aim of this work was to investigate the combined use of coatings and nitrogen atmosphere during the postharvest of the Manzanilla variety to optimize the quality of these fruits processed as Spanish-style green olives.

\section{Materials and methods}

\subsection{Experiments simulating mechanical harvesting}

\subsubsection{Preliminary survey of coatings}

Fruit of the Manzanilla variety (Olea europaea L.) were hand-harvested from an olive grove located in the province of Seville (Spain) and transported to the laboratory within $1 \mathrm{~h}$. They had an optimal green-yellow color and were macroscopically free of damage and disease. Simulated bruising was carried out in a controlled manner by allowing the fruit to drop freely onto the cement floor from a height of a $2.5 \mathrm{~m}$. The damaged fruit were dipped in several coating solutions for $5 \mathrm{~s}$ and stored under a nitrogen atmosphere for $3 \mathrm{~h}$. Subsequently, the olives were exposed to the open air for $15 \mathrm{~min}$ and submerged in a $0.5 \mathrm{M} \mathrm{NaOH}$ solution (lye) for $7 \mathrm{~h}$ until the alkali penetrated two-thirds of the way to the pit. Finally, the olives were washed with tap water for $12 \mathrm{~h}$ and exposed to the open air for 15 min in order to visually detect brown spots on the fruit surface by table olive experts. The coatings used in this experiments were $1 \%$ glycerol, and several commercial coatings employed for citrus products such as Citrosol 686 $($ Carnauba + Shellac), Citrosol 680 (Carnauba+ Shellac), Citrosol 652 (Polyethylene + Shellac) and Citrosol 642 (Polyethylene + Shellac) (Productos Citrosol S. A., Valencia, Spain). These coatings are marketed for maintaining the commercial quality of fruits, and particularly to control postharvest diseases. 


\subsubsection{Study of phenolic compounds and PPO in damaged olives}

Simulated bruised olives of the Manzanilla variety were left in the open air for $24 \mathrm{~h}$ or alternatively under nitrogen atmosphere for $23 \mathrm{~h}$ plus one hour in the open air.

In another experiment, bruised olives were stored (i) under a nitrogen atmosphere for $23 \mathrm{~h}$, (ii) under a nitrogen atmosphere for $23 \mathrm{~h}$ plus one hour in the open air, and (iii) dipped in a Citrosol 642 solution for $5 \mathrm{~s}$, left under the nitrogen atmosphere for $23 \mathrm{~h}$ and finally in the open air for $3 \mathrm{~h}$.

Phenolic compounds were analyzed in the bruised and unbruised areas of the damaged olives according to the method described elsewhere (Sánchez et al., 2013).

133 Briefly, these substances were extracted from the olive pulp with dimethyl sulfoxide 134 (DMSO). Around $0.1 \mathrm{~g}$ of olive pulp from bruised and unbruised areas were put into contact with $0.5 \mathrm{~mL}$ DMSO, vortexed for $1 \mathrm{~min}$ and sonicated for $5 \mathrm{~min}$. After $30 \mathrm{~min}$, the mixture was centrifuged at $6000 \mathrm{~g}$ for $5 \mathrm{~min}$, and $0.25 \mathrm{~mL}$ of the supernatant were diluted with $0.5 \mathrm{~mL}$ DMSO and $0.25 \mathrm{~mL}$ of $0.2 \mathrm{mM}$ syringic acid (internal standard). Finally, the mixture was filtered through $0.22 \mu \mathrm{m}$ pore size nylon filter and $20 \mu \mathrm{L}$ were injected into the chromatograph. All analyses were run in triplicate.

Polyphenol oxidase (PPO) activity was also determined in the bruised and unbruised areas of the damaged olives. The enzyme extraction was carried out from a protein precipitate as described elsewhere (Sciancalepore \& Longone, 1984). Acetone

143 powders were obtained from $50 \mathrm{~g}$ of olive pulp homogenized with $100 \mathrm{~mL}$ of cold acetone $\left(-30{ }^{\circ} \mathrm{C}\right)$ containing $2.5 \mathrm{~g}$ of polyethylene glycol. The residue was re-extracted three times with $100 \mathrm{~mL}$ of cold acetone, obtaining a white powder that was dried overnight at room temperature to remove residual acetone. The acetone powder $(0.5 \mathrm{~g})$ was suspended in $20 \mathrm{~mL}$ of a $0.1 \mathrm{M}$ phosphate buffer, containing $1 \mathrm{M} \mathrm{KCl}$ and the $\mathrm{pH}$ was adjusted at 6.2 units with $\mathrm{NaOH}$. The suspension was stirred at $4{ }^{\circ} \mathrm{C}$ for 30 min and then centrifuged at $15550 \mathrm{~g}$ for $20 \mathrm{~min}$ at $4{ }^{\circ} \mathrm{C}$. The pellet was discarded and the supernatant divided into two aliquots; one was used as the active crude enzymatic extract, and the other was boiled for 30 min to obtain the denatured enzymatic extract.

The PPO activity was determined spectrophotometrically by using a Shimadzu UV-1800 spectrophotometer as described elsewhere (Hornero-Méndez, Gallardo-

154 Guerrero, Jarén-Galán \& Mínguez-Mosquera, 2002). All measurements of PPO activity were carried out with 4-methylcatechol as substrate by measuring the change in absorbance at $410 \mathrm{~nm}$ at $25{ }^{\circ} \mathrm{C}$ for $10 \mathrm{~min}$ at intervals of $5 \mathrm{~s}$. The incubation mixture 
157 contained $0.5 \mathrm{~mL}$ of enzyme preparation and $2.5 \mathrm{~mL}$ of $0.1 \mathrm{M}$ sodium citrate buffer at $\mathrm{pH} 5$ containing $0.02 \mathrm{M}$ of substrate. The assay mixture with the denatured enzymatic extract served as the control. One unit of enzymatic activity was defined as the amount

160 of the enzyme giving, under the above-mentioned conditions, a change in absorbance of 1610.05 unit AU/min (e.a.u.). Data were expressed as e.a.u./mL of enzymatic extract. All 162 reactions were carried out in duplicate.

\subsection{Postharvest storage and processing of mechanically harvested olives}

\subsubsection{Plant material}

Olives of the Manzanilla variety were mechanically harvested by trunk shakers from olive groves located in the province of Seville (Spain) during the season 2012/2013. Leaves and small branches were removed at the groves and the olives were transported in less than 30 min to the factory. All olives were harvested at their optimal green-yellow surface color.

\subsubsection{Experiment $A$}

174 Upon arrival at the olive factory, $4 \mathrm{~kg}$ of fruit were covered with a $0.5 \mathrm{M} \mathrm{NaOH}$ solution and maintained until the alkali penetrated two-thirds of the way to the pit of the olives (ca. $7 \mathrm{~h}$ ) (Control $0 \mathrm{~h})$. Another lot of damaged fruit was left in the open air for 5 $\mathrm{h}$ before the alkali treatment (Control $5 \mathrm{~h}$ ). Three lots of olives were dipped in $5 \%$ glycerol, $100 \%$ Citrosol 642 and $50 \%$ Citrosol 642 for $5 \mathrm{~s}$ before the fruit were stored under a nitrogen atmosphere in $5 \mathrm{~L}$ stainless steel containers for $5 \mathrm{~h}$. After the storage period in the inert atmosphere, these olives were left in the open air for $15 \mathrm{~min}$ and dipped in the alkali solution.

All the fruit submitted to the alkaline treatment was then washed with tap water for $12 \mathrm{~h}$ and subsequently covered with a $12 \% \mathrm{NaCl}$ solution where spontaneous lactic acid fermentation occurred for months.

All experiments were run in duplicate, and the quality analyses were carried out after 8 months of fermentation.

\subsubsection{Experiment $B$}

189 Because of the great variability among olive batches, a new experiment was 190 design to confirm results obtained in Experiment A but treatment with glycerol was 
191 eliminated. The damaged fruit was treated directly with the $\mathrm{NaOH}$ solution (Control) or

192 stored under a nitrogen atmosphere for $5 \mathrm{~h}$. In the latter case, two lots of the olives were

193 dipped in $100 \%$ Citrosol 642 or $50 \%$ Citrosol 642 solutions for 5 s previously to the

194 inert atmosphere storage. Olives were left in the open air for $15 \mathrm{~min}$ and dipped in the

195 alkali solution. All fruits were then processed as mentioned in Experiment A.

196 This Experiment B was run with olives from two different groves (batches A and

197 B) and in duplicate. The quality analyses were carried out after 8 months of

198 fermentation.

\subsubsection{Analyses associated with controlling fermentation}

201 The determination of $\mathrm{pH}$, salt and acidity (free and combined) of the brines was 202 carried out using the routine methods described elsewhere (Medina, García, Romero \& 203 Brenes, 2011).

\subsubsection{Color}

The colorimetric measurements of olives were made using a BYK-Gardner model 9000 Color-view spectrophotometer, equipped with computer software to calculate the CIE $L^{*}$ (lightness), $a^{*}$ (redness), and $b^{*}$ (yellowness) parameters. Interference by stray light was minimized by covering samples with a box that had a mat black interior. The data from each measurement are the average of 20 olives.

\subsubsection{Texture}

The firmness of olives was measured using a Kramer shear compression cell

214 coupled to a Texture Analyzer TA.TX plus (Stable Microsystems, Godalming, UK).

215 The crosshead speed was $200 \mathrm{~mm} / \mathrm{min}$. Firmness was the mean of 10 replicate

216 measurements, each of which was performed on 3 pitted olives, and expressed as

217 Newton/100 g pitted olives.

\subsubsection{Assessment of olive quality}

The visual quality of olives fermented for 8 months was determined by table olive experts. The appearance was estimated by measuring the extent of the browned area on each olive of a lot of $500 \mathrm{~g}$. The assessment was based on the following hedonic scale: A (olives free of any brown spots in an area larger than $3 \mathrm{~mm}^{2}$ ), B (olives free of any brown spots in an area larger than $9 \mathrm{~mm}^{2}$ ) and $\mathrm{C}$ (olives with brown spots covering 
225

226

227

228

229

230

231

232

233

234

235

236

237

238

239

240

241

242

243

244

245

246

247

248

249

250

251

252

253

254

255

256

257

258

areas larger than $9 \mathrm{~mm}^{2}$ ). It was expressed as percentage of olives corresponding to each category. It must be noted that the international standard for table olives establishes blemished fruit defects as "Olives with marks on the skin that measure more than $9 \mathrm{~mm}^{2}$ in surface area" (IOC, 2004).

\subsection{Statistical analysis}

Statistical comparisons of the mean values for each experiment were performed by one-way analysis of variance (ANOVA), followed by Duncan's multiple range test $(\mathrm{P}<0.05)$ using STATISTICA software version 6.0 (Stat-Soft, 2001). Data presented as percentages were arcsin transformed, prior to the statistical analysis.

\section{Results and discussion}

\subsection{Preliminary survey of coatings}

Bruising was simulated on Manzanilla olives by dropping the fruit onto a flat surface as has been proposed by several researchers (Saracoglu et al., 2011; JiménezJiménez et al., 2103). Subsequently, the fruits were dipped in several coating solutions, stored in nitrogen for $3 \mathrm{~h}$, exposed to air for $15 \mathrm{~min}$, treated with an $\mathrm{NaOH}$ solution for $7 \mathrm{~h}$, washed for $12 \mathrm{~h}$ and exposed to air for $15 \mathrm{~min}$. Visual observation of the fruit indicated that the incidence of brown spots was in the order of non-coating $>1 \%$ glycerol $>$ Citrosol 680>Citrosol 686>Citrosol 652>Citrosol 642. Glycerol is commonly used as a plastisizer in edible coatings (Malmiri, Osman, Tan \& Rahman, 2012), although it also showed some effect in protecting harvested olives from bruising (Sánchez, et al., 2013). However, the greatest anti-browning effect was observed for the commercial coatings employed for citrus products (Pereira et al., 2013), particularly Citrosol 642. This coating was chosen for the next experiments carried out with mechanically harvested olives.

\subsection{Storage of coated olives under nitrogen atmosphere. Experiment $A$}

The fruit placed directly into the alkaline solution (Control $0 \mathrm{~h}$ ) presented the highest percentage of less injured olives (grade A), followed by the coated fruit (Fig. 1). Both the olives coated with glycerol and those left in the open air for $5 \mathrm{~h}$ before the 
259 alkaline treatment had the lowest percentage of grade A olives. By contrast, the lowest

260 percentage of olives graded as B was found for the control treatment, followed by the 261 coated olives with Citrosol 642, glycerol and fruit exposed to the open air for $5 \mathrm{~h}$ before 262 the $\mathrm{NaOH}$ treatment. Hence, coating with glycerol did not prevent the appearance of 263 bruising as it was previously found (Sánchez et al., 2013). Consequently, olives must be 264 processed immediately after they are mechanically harvested because brown spots are 265 formed in a few hours (Jiménez-Jiménez et al., 2013) but this treatment is not feasible 266 because growers take several hours to transport the fruit to the factories. Alternatively 267 olives could be coated at the groves with products such as Citrosol 642 and stored under a nitrogen atmosphere to improve the quality of the final fermented product.

\subsection{Storage of coated olives under nitrogen atmosphere. Experiment B}

In order to confirm the results obtained in Experiment A, new postharvest experiments were carried out with olives mechanically harvested in two different groves (batches A and B). It was observed for both batches that brown spots appeared rapidly once the nitrogen atmosphere was released if coatings were not used (Fig. 2). By contrast, olives coated with Citrosol 642 showed a higher percentage of Grade A fruit than the rest of the treatments which was statistically significant for batch A. It must be noted that the olives from this batch A coated with 100\% Citrosol 642 had a significantly higher percentage of olives graded as A than the control. As can be expected, the percentage of olives graded as B was lower for those coated with Citrosol 642 than the other treatments. The aim of this new technology was to achieve processed olives with at least a similar quality than using the control method (directly alkaline treatment), which was reached for fruit of both batches A and B.Therefore, coating the olives prevented the formation of brown spots once the nitrogen atmosphere was eliminated and the fruits were exposed to the open air for $15 \mathrm{~min}$, particularly if the Citrosol 642 solution was used without any dilution. It seems that the coating formed a barrier against oxygen diffusion, and it could allow processors to handle olives in their factories before they are immersed in the $\mathrm{NaOH}$ solution. The high percentage of olives graded as $\mathrm{C}$ when they were stored in nitrogen without any coating must also be highlighted, in particular for those of batch $\mathrm{B}$, which means that the browning of the injured areas is accelerated when the anoxic condition is eliminated. 
Other important quality parameters of Spanish-style green olives are their color and texture. The effect of the combined use of coating and nitrogen atmosphere on the firmness of processed olives was different for batches A and B (Fig. 3). The firmness of the fruit from batch $\mathrm{B}$ was not affected by the coating or the nitrogen atmosphere during the postharvest period. By contrast, the olives from batch A, placed directly into the $\mathrm{NaOH}$ solution showed stronger firmness after fermentation than those stored under nitrogen with and without any coating. It has been reported that harvested olives lose firmness when they are exposed to air (García, Brenes, Romero \& Garrido, 1995) but no data are available regarding such parameter under anoxic conditions although neither the anoxic conditions nor coatings cause loss of firmness in other food products (Hernández-Muñoz et al., 2008; Song, Gao, Chen, Mao, Zhou, Chen \& Jiang, 2009).

303 Due to the variability in raw material and the contradictory data found for these two batches, it is however necessary to assess the effect on firmness of the coating and nitrogen postharvest storage on several new batches.

With regard to the color of the fermented olives, the storage under nitrogen of coated or non-coated olives did not affect the surface color of the fermented fruit (data not shown).

\subsection{Study of phenolic compounds in damaged olives}

In a previous work (Sánchez et al., 2013), we found that brown spots were formed during the storage of damaged olives in the open air due to the enzymatic oxidation of the polyphenol oleuropein. Besides, no degradation product from the oleuropein

315 hydrolysis was detected in the bruised areas of damaged olives. In our experiment of 316 simulating mechanical harvesting, the concentration of oleuropein in the unbruised area

317 of the fruit did not change after the storage of damaged olives either in the open air or in 318 the nitrogen atmosphere (Fig. 4). By contrast, the concentration of this phenolic 319 compound in the bruised area decreased progressively with the time the fruit was exposed to the open air, as expected (García et al., 2008; Sánchez et al., 2013). It has also been proposed that damage in tissues produces an increased activity of the enzymes involved in polyphenol synthesis and therefore an accumulation of these phenolic substances (Saltveit, 2000). However, we did not detect an increase in oleuropein concentration but a decrease due to oxidation. 
Surprisingly, the highest decrease in oleuropein concentration occurred in the bruised area of the olives stored under nitrogen for $23 \mathrm{~h}$ and then exposed to the open air for another hour. It seemed that oleuropein rapidly oxidized once the nitrogen atmosphere was released. Nevertheless, it was found that the concentration of oleuropein diminished to a large extent in the bruised area just during the storage of damaged olives under nitrogen, and at the same time, a high increase in the dialdehydic form of decarboxymethyl elenolic acid linked to hydroxytyrosol (HyEDA) was detected (Fig. 5). These data mean that the anoxic conditions retarded the enzymatic oxidation of the oleuropein but not the enzymatic hydrolysis of this phenolic glucoside by the action of the $\beta$-glucosidase enzyme.

Moreover, HyEDA is a product of the oleuropein hydrolysis which rapidly disappeared from the bruised area of the olives stored under nitrogen and to a lesser extent in the bruised area of coated fruit (Fig. 5). This substance like oleuropein is an $o$ diphenol that oxidizes to form brown spots. In conclusion, the storage of harvested olives under nitrogen did not allow for the oxidation of oleuropein because of the absence of oxygen but the glucoside was enzymatically hydrolyzed to form HyEDA which rapidly oxidized when the anoxic conditions were eliminated. Likewise, the oxidation of HyEDA and the residual oleuropein was retarded when the fruits were coated.

Figure 6 shows the activity of PPO in the bruised and unbruised areas of stored olives. First, the much higher activity of PPO in the bruised compared to the unbruised area of fruit stored in the open air must be noted. A gradual increase in the PPO activity has also been observed during the ambient storage of fresh-cut eggplant (Mishra et al., 2012). In addition, the coating seems to delay the increase in PPO activity of stored fruits (Jian \& Li, 2001; Supapvanich et al., 2012). In our experiments, a lower PPO activity in the unbruised area of coated olives than non-coated was observed but the most important finding was the lower PPO activity found in the bruised area of both coated and non-coated fruit when they were stored under nitrogen. This low activity could also contribute to retarding the browning in damaged areas.

The results obtained in this study indicated that the combined use of nitrogen atmosphere and commercial coatings can minimize the bruising damage produced in Manzanilla olives that were mechanically harvesting and processed as Spanish-style green olives. However, the design of anoxic containers at industrial level and 
359

360

361

362

363

364

365

366

367

368

369

370

371

372

373

374

375

376

377

378

379

380

381

382

383

384

385

386

387

388

389

390

391

392

authorizing of the use of coatings in the table olive sector will be required before this technology is implemented by growers.

\section{Acknowledgments}

The authors are grateful to Interaceituna Association and the Spanish Government (project AGL-2009-07512) for financial support. They also wish to thank Maestre Benjumea Hnos. C. B., Explotaciones Agrícolas Las Moreras S. A., and Alberoliva S. L. for providing olive samples. Thanks also go to Elena Cabello for technical assistance and Producctos Citrosol S. A for supplying the coatings.

\section{References}

Ben-Shalom, N., Harel, E., \& Mayer, A. M. (1978). Enzymatic browning in green olives and its prevention. Journal of the Science of Food and Agriculture, 29, 398402.

Chauhan, O. P., Raju, P. S., Singh, A., \& Bawa, A. S. (2011). Shellac and aloe-gelbased surface coatings for maintaining keeping quality of apple slices. Food Chemistry, 126, 961-966.

Ferguson, L. (2006). Trends in olive harvesting. Grasas y Aceites, 57, 9-15.

Gambella, F., Dimauro, C., \& Paschino, F.(2013). Evaluation of fruit damage caused by mechanical harvesting of table olives. T. ASABE, 56, 1267-1272.

García, P., Brenes, M., Romero, C., \& Garrido, A. (1995). Respiration and physicochemical changes in harvested olive fruits. Journal of Horticultural Science, 70, 925-933.

García, A., Romero, C., Medina, E., García, P., de Castro, A., \& Brenes, M. (2008). Debittering of olives by polyphenol oxidation. Journal of Agricultural and Food Chemistry, 56, 11862-11867.

Hernández-Muñoz, P., Almenar, E., Del Valle, V., Velez, D., \& Gavara, R. (2008). Effect of chitosan coating combined with postharvest calcium treatment on strawberry (Fragaria x ananassa) quality during refrigerated storage. Food Chemistry, 110, 428-435.

Hornero-Méndez, D., Gallardo-Guerrero, L., Jarén-Galán, M., \& Mínguez-Mosquera, M. I. (2002). Differences in the activity of superoxide dismutase, polyphenol 
oxidase and $\mathrm{Cu}-\mathrm{Zn}$ content in the fruits of Gordal and Manzanilla olive varieties. Zeitschrift Naturforsch A, 57, 113-120.

IOC (International Olive Council), 2004. Trade standards applying to table olives COI/OTNC no. 1, Madrid, Spain.

Jiang, Y., \& Li, Y. (2001). Effects of chitosan coating on postharvest life and quality of longan fruit. Food Chemistry, 73, 139-143.

Jiménez-Jiménez, F., Castro-García, S., Blanco-Roldán, G. L., Ferguson, L., Rosa, U. A., \& Gil-Ribes, J. A. (2013). Table olive cultivar susceptibility to impact bruising. Postharvest Biology and Technology, 86, 100-106.

Malmiri, H. J., Osman, A., Tan, C. P., \& Rahman, R. A. (2012). Effects of edible surface coatings (sodium carboxymethyl cellulose, sodium caseinate and glycerol) on storage quality of Berangan banana (Musa Sapientum cv. Berangan) using response surface methology. Journal of Food Processing and Preservation, 36, 252-261.

Medina, E., García, P., Romero, C., \& Brenes, M. (2011). Recycling preservation Solutions in black ripe olive processing. International Journal of Food Science and Technology, 46, 1685-1690.

Mishra, B. B., Gautama, S., \& Sharma, A. (2012). Browning of fresh-cut eggplant: impact of cutting and storage. Postharvest Biology and Biotechnology, 67, 44-51.

Njombolwana, N. S., Erasmus, A., \& Fourie, P. H. (2013). Evaluation of curative and protective control of Penicilium digitatum following imazalil application in wax coating. Postharvest Biology and Biotechnology, 77, 102-110.

Pereira, G. D., Machado, F. L. D., \& de Costa, J. M. C. (2013). Quality of "Delta Valencia" orange Brown in semiarid climate and stored under refrigeration alter coating with wax. Food Science and Technology, 33, 276-281.

Ramírez, E., García-García, P., De Castro, A., Romero, C., \& Brenes, M. (2013). Debittering of black dry-salted olives. European Journal of Lipid Science and Technology, 115, 1319-1324.

Rejano, L., Sánchez, A. H., \& Vega, V. (2008). New trends on the alkaline treatment “cocido" of Spanish-style green table olives. Grasas y Aceites, 59, 195-202.

Saltveit, M. E. (2000). Wound induced changes in phenolic metabolismo and tissue Browning are altered by heat schok. Postharvest Biology and Biotechnology, 21, 61-69. 
426

427

428

429

430

431

432

433

434

435

436

437

438

439

440

441

442

443

444

445

446

447

448

449

Sánchez, A. H., Romero, C. Ramírez, E., \& Brenes, M. (2013). Storage of mechanically harvested Manzanilla olives under controlled atmospheres. Postharvest Biology and Biotechnology, 81, 60-65.

Saracoglu, T., Ucer, N., \& Ozarslan, C. (2011). Engineering properties and susceptibility to bruising damage of table olive (Olea europaea) fruit. International Journal of Agriculture and Biology, 13, 801-805.

Sciancalepore, V., \& Longone, V. (1984). Polyphenol oxidase activity and browning in green olives. Journal of Agricultural and Food Chemistry, 32, 320-321.

Segovia-Bravo, K., García-García, P., López-López, A., \& Garrido-Fernández, A. (2012). Effect of inerte atmosphere on the postharvest Browning of Manzanilla olives and optimization by response surface methodology of the aquous treatments. Journal of Food Science, 77, S194-S201.

Song, L., Gao, H., Chen, H., Mao, J., Zhou, Y., Chen, W., \& Jiang, Y. (2009). Effects of short term anoxic treatment on antioxidant ability and membrane integrity of postharvest kiwifruit during storage. Food Chemistry, 114, 1216-1221.

Supapvanich, S., Prattama, P., \& Tepsorn, R. (2012). Browning inhibition in fresh-cut rose apple fruit cv. Taaptimjaan using konjac glucomannan coating incorporated with pineapple fruit extract. Postharvest Biology and Biotechnology, 73, 1-4.

Zipori, I., Dag, A., Tugendhaft, Y., \& Birger, R. (2014). Mechanical harvesting of table olives: harvest efficiency and fruit quality. Hortscience, 49, 55-58. 
452 Fig. 1. Quality of olives processed according to Experiment A. Mechanically harvested 453 fruits were maintained for $5 \mathrm{~h}$ under nitrogen and subsequently left in the open air for $45415 \mathrm{~min}$ before processing as Spanish-style green olives, except for olives of the control 455 treatment, which were placed directly into the $\mathrm{NaOH}$ solution (Control $0 \mathrm{~h}$ ) or dipped in 456 the alkaline solution after $5 \mathrm{~h}$ in the open air (Control, $5 \mathrm{~h}$ in the open air). Analyses 457 were carried out after 8 months of fermentation. Error bars indicate standard deviation 458 of duplicates. Different letters on the bars mean significant differences for the same $\mathrm{X}$ value according to a Duncan's multiple range test $(p<0.05)$.

460

461 Fig. 2. Quality of olives processed according to Experiment B. Mechanically harvested 462 fruits were maintained for $5 \mathrm{~h}$ under nitrogen and subsequently left in the open air for $46315 \mathrm{~min}$ before processing as Spanish-style green olives, except for olives of the control 464 treatment, which were placed directly into the $\mathrm{NaOH}$ solution. Analyses were carried 465 out after 8 months of fermentation. Error bars indicate standard deviation of duplicates. 466 Different letters on the bars mean significant differences for the same $\mathrm{X}$ value according 467 to a Duncan's multiple range test $(p<0.05)$.

469 Fig. 3. Firmness of olives processed according to Experiment B. Analyses were carried 470 out after 8 months of fermentation. Error bars indicate standard deviation of duplicates. . 471 Different letters on the bars mean significant differences for the same $\mathrm{X}$ value according 472 to a Duncan's multiple range test $(p<0.05)$.

473

474 Fig. 4. Concentration of oleuropein in unbruised and bruised areas of olives subjected to 475 simulated mechanical harvesting, and stored under air or nitrogen. Error bars indicate 476 standard deviations of triplicates. Different letters on the bars mean significant 477 differences for the same $\mathrm{X}$ value according to a Duncan's multiple range test $(p<0.05)$.

479 Fig. 5. Concentration of oleuropein and HyEDA (dialdehydic form of decarboxymethyl 480 elenolic acid linked to hydroxytyrosol) in the bruised areas of olives subjected to 481 simulated mechanical harvesting. The concentration of oleuropein in the unbruised area 482 was $43840 \mathrm{mg} / \mathrm{kg}$. Error bars indicate standard deviation of triplicates. Different letters 
483 on the bars mean significant differences for the same $\mathrm{X}$ value according to a Duncan's 484 multiple range test $(p<0.05)$.

485

486 Fig. 6. Activity of PPO in the bruised and unbruised areas of olives subjected to 487 simulated mechanical harvesting. Fruits were left in the open air for $24 \mathrm{~h}$ or under 488 nitrogen for $23 \mathrm{~h}$ and then in the open air for $1 \mathrm{~h}$ after impact. Bars mean standard 489 deviation of duplicates. n.d., not detected. Different letters on the bars mean significant 490 differences for the same $\mathrm{X}$ value according to a Duncan's multiple range test $(p<0.05)$. 491 


$$
\begin{array}{ll}
\square \text { Control } 0 ~ h & \square \text { Control, } 5 \text { h in open air } \\
\square N_{2}+\text { Citrosol } 642 & \square N_{2}+\text { Citrosol } 642(50 \%) \\
\square N_{2} \text { glycerol (5\%) } &
\end{array}
$$

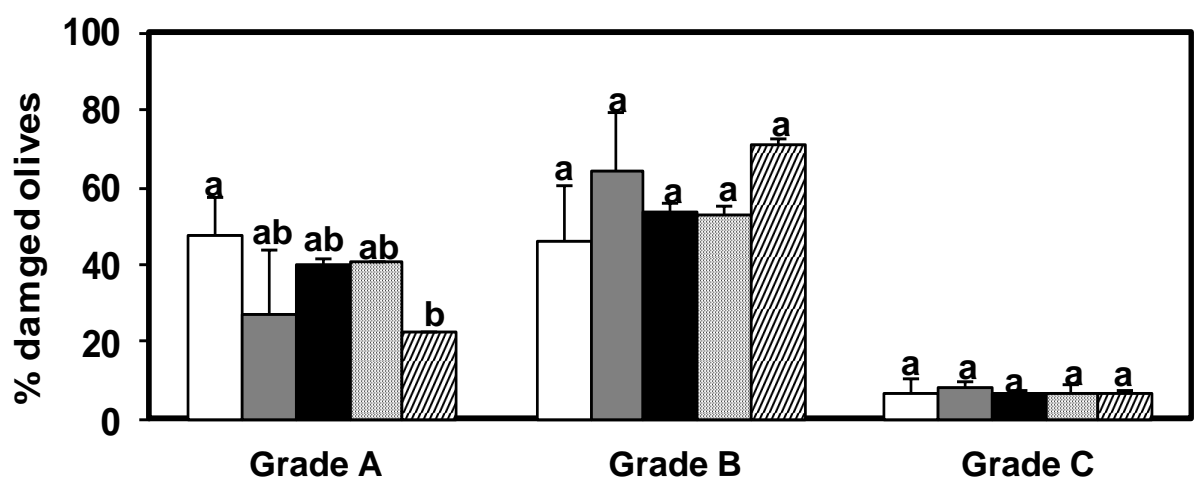



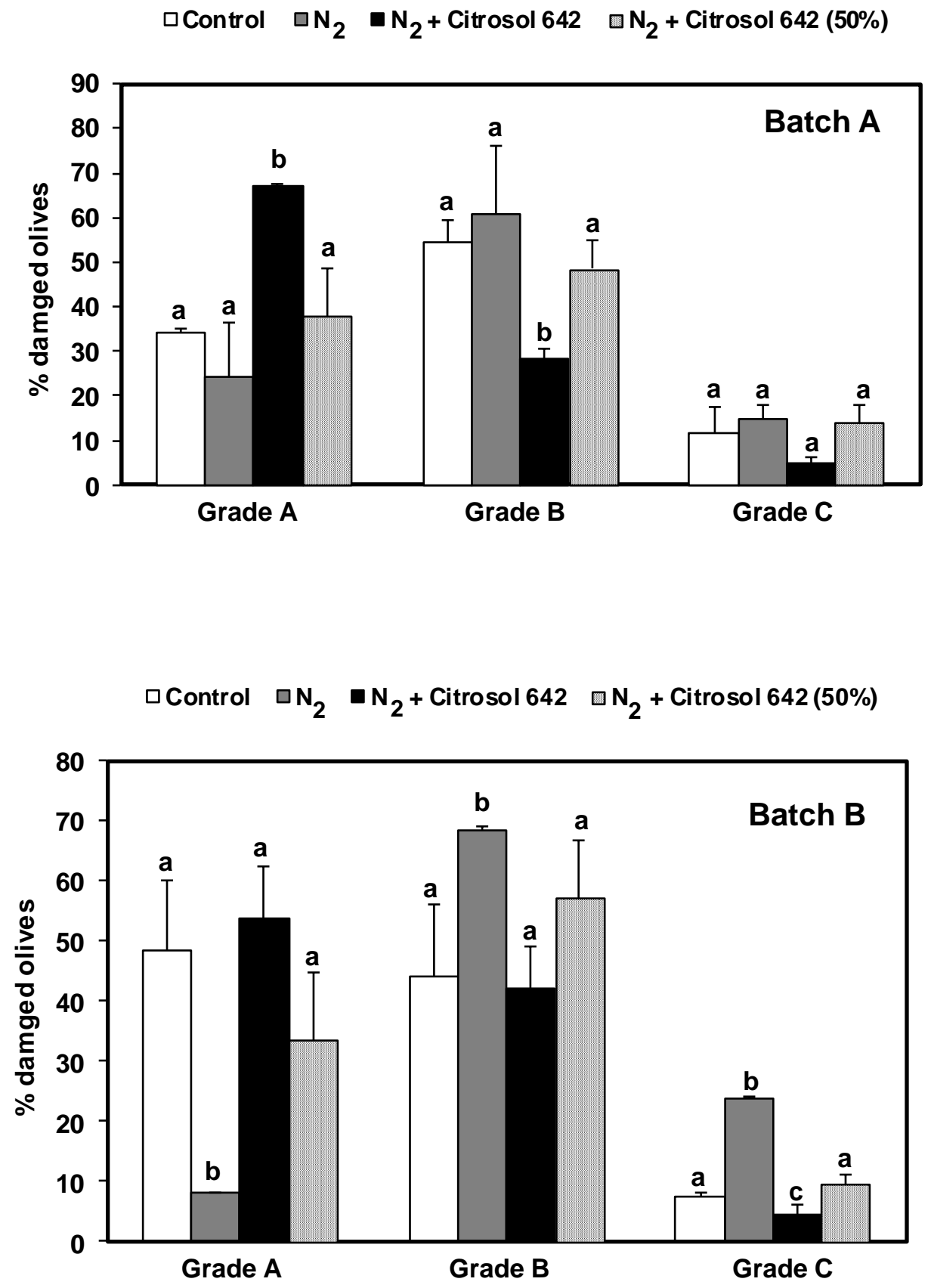
$\square$ Control $\square N_{2} \quad N_{2}+$ Citrosol $642 \square N_{2}$ + Citrosol $642(50 \%)$

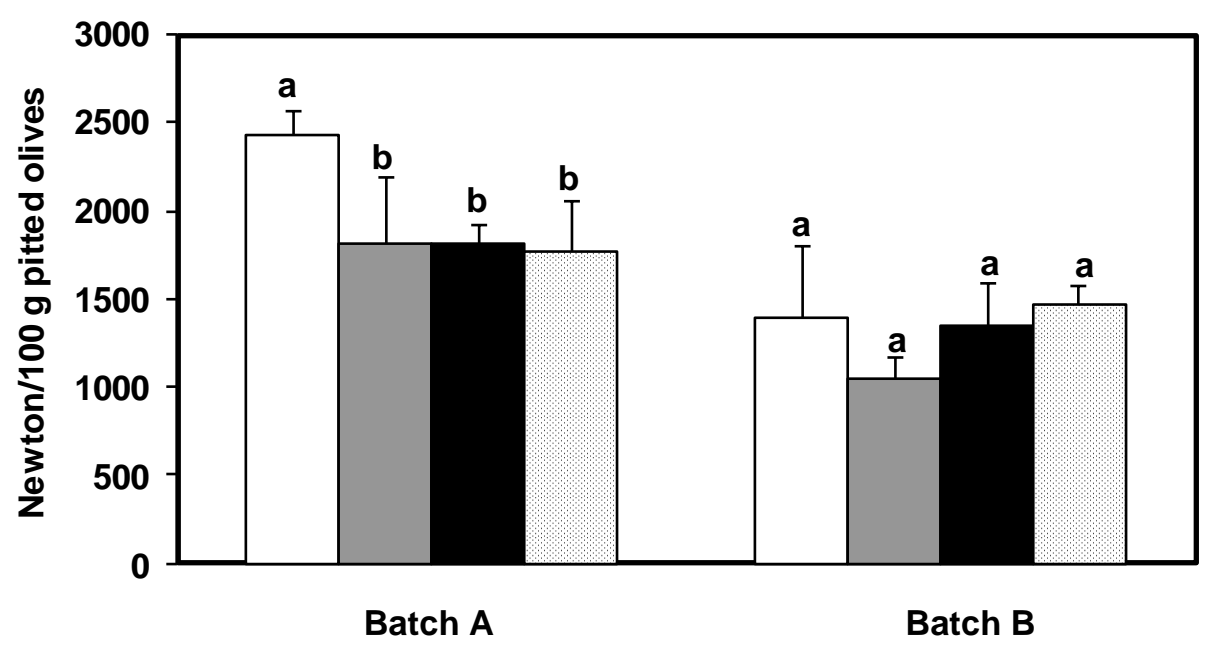


$\square$ Nitrogen $23 \mathrm{~h}$ Nitrogen $23 \mathrm{~h}+$ air $3 \mathrm{~h} \square$ Nitrogen/Citrosol $64223 \mathrm{~h}+$ air $3 \mathrm{~h}$

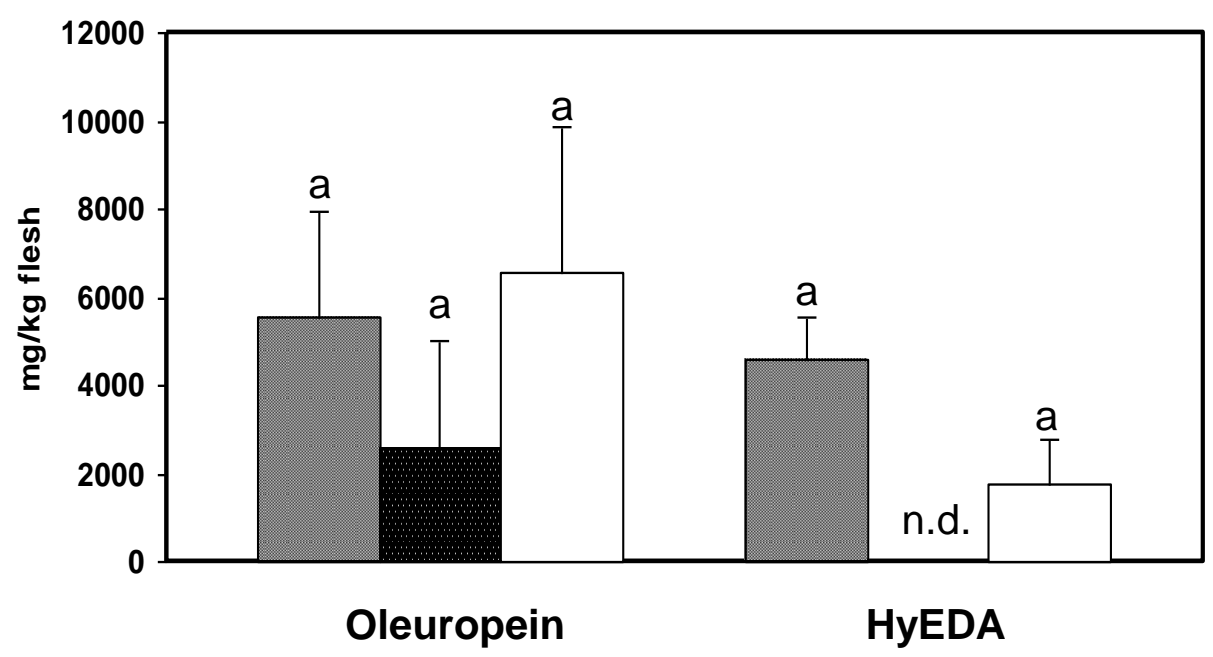


$\square$ Air $\square$ Nitrogen $\square$ Nitrogen + Citrosol 642

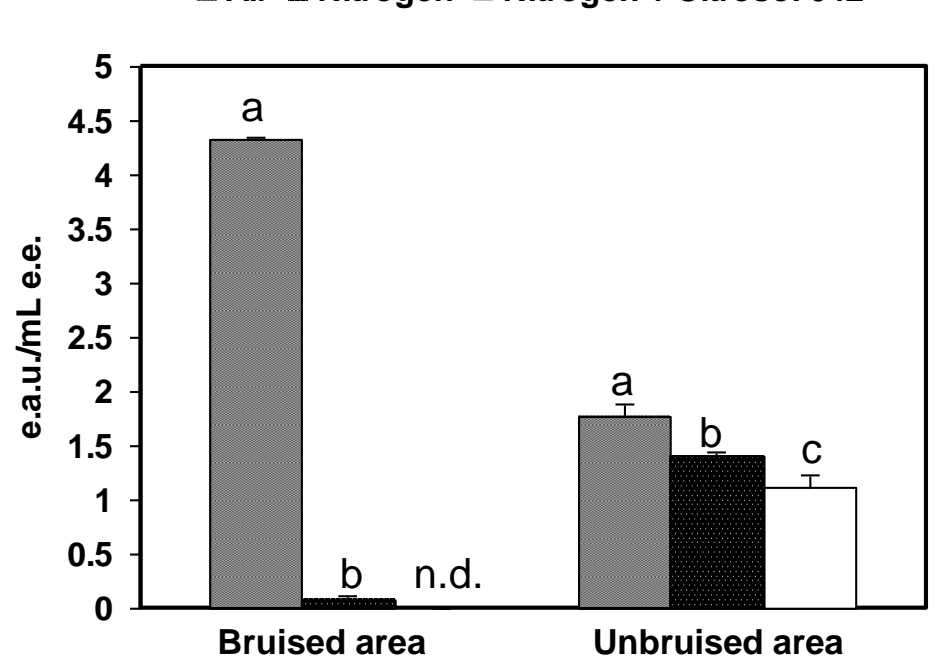

Figure(s) 